\title{
Level and Timing of Implanon Discontinuation and Associated Factors among Women Who Used Implanon in Andabet District, Public Health Facilities, North-West Ethiopia
}

\author{
Gizachew Worku Dagnew $\mathbb{D}^{1},{ }^{1}$ Yared Mulu Gelaw, ${ }^{2}$ Melash Belachew Asresie, ${ }^{1}$ \\ and Zelalem Alamrew Anteneh ${ }^{3}$ \\ ${ }^{1}$ Department of Reproductive Health and Population Studies, School of Public Health, College of and Health Science, \\ Bahir Dar University, Bahir Dar, Ethiopia \\ ${ }^{2}$ Department of Health Service Management, School of Public Health, College of and Health Science, Bahir Dar University, \\ Bahir Dar, Ethiopia \\ ${ }^{3}$ Department of Biostatistics and Epidemiology, School of Public Health, College of and Health Science, Bahir Dar University, \\ Bahir Dar, Ethiopia
}

Correspondence should be addressed to Gizachew Worku Dagnew; giz.work12@gmail.com

Received 16 November 2020; Revised 28 June 2021; Accepted 26 July 2021; Published 6 August 2021

Academic Editor: Ali Khani jeihooni

Copyright (c) 2021 Gizachew Worku Dagnew et al. This is an open access article distributed under the Creative Commons Attribution License, which permits unrestricted use, distribution, and reproduction in any medium, provided the original work is properly cited.

\begin{abstract}
Background. Implanon discontinuation is unacceptably high in developing countries, including Ethiopia. Furthermore, there is an observed problem of high unintended pregnancy after method discontinuation that strides to program failure. Therefore, the purpose of this study was to assess the level and determinants of Implanon discontinuation among women who used Implanon in Andabet district, public health facilities, North-West Ethiopia, 2017. Methods. Facility-based cross-sectional study design was employed among 537 women from Feb. 03 to April 28, 2017. Study participants were selected using a systematic random sampling technique. A face-to-face interview was employed to collect data. Epi-Info version 7 was used for data entry and SPSS version 20 for analysis. Both descriptive and analytical statistical analysis was computed. On multivariable binary logistic regression, a $p$ value of less than 0.05 was used to declare statistical significance. Results. About $37 \%$ of Implanon users have discontinued the method before the intended time. About $86 \%$ of them discontinued Implanon before two years of insertion. Women who had no live child $(\mathrm{AOR}=2.17,95 \% \mathrm{CI}$ : 1.25-3.77), women who did not receive preinsertion counseling $(\mathrm{AOR}=1.85,95 \% \mathrm{CI}: 1.15-2.97)$, women who developed Implanon-related side effect $(\mathrm{AOR}=5.17,95 \% \mathrm{CI}: 3.18-8.40)$, and women who did not satisfy by the service provided ( $\mathrm{AOR}=5.40,95 \% \mathrm{CI}$ : 3.04-9.57) had higher odds of Implanon discontinuation. On the other hand, women who received appointment follow-up (AOR $=0.23,95 \%$ CI: $0.13-0.41)$ had lower odds of Implanon discontinuation. Conclusions. The level of Implanon discontinuation before its intended time was high in the district. Hence, strengthening preinsertion counseling and appointment follow-up as well as improving the clients' level of service satisfaction could increase Implanon's continuation.
\end{abstract}

\section{Introduction}

Implanon is a second-generation single-rod progestogenonly contraceptive implant with a length of $40 \mathrm{~mm}$ and a diameter of $2 \mathrm{~mm}$ containing $68 \mathrm{mg}$ of etonogestrel dispersed in a membrane of ethylene-vinyl acetate. It delivers ENG at a dose sufficient to suppress ovulation in every cycle through- out the 3 years of use [1-3]. This single-rod progestogen subdermal (etonogestrel) is developed as a need to reduce some of the problems associated with the six implant systems, Norplant by 2008, and it is prequalified by the World Health Organization (WHO) in 2010 [2, 4]. Implanon has the most effective implants to prevent pregnancy compared to other short-acting contraceptives $[2,5,6]$. 
Globally, 7\% of married or in-union reproductive-age women were using injectable contraceptives [7, 8]. Even though millions of reproductive-age women were using implants, its contribution among all method mix was not more than $1 \%$. And significant numbers of women discontinue the method before its intended period [7]. Across the world, the percentage of Implanon discontinuation ranges from $3 \%$ in Burkina Faso to $27 \%$ in Yemen in the first year and 23 percent in Liberia to 69 percent in Yemen at the end of three years of insertion [9].

In 2009, the Ethiopian Federal Ministry of Health (FMOH) launched an Implanon scale-up program to improve the availability of long-acting reversible contraceptive (LARC) methods at the community level. The Integrated Family Health Program (IFHP) supports the $\mathrm{MOH}$ to train Health Extension Workers (HEWs) as a cadre of frontline health workers on Implanon insertion [10]. The scale-up program was successful in reaching all communities by LAR. Consequently, Implanon use among married or in-union women was increased from $3.4 \%$ in 2011 to $8 \%$ in 2016 [11]. Despite this improvement, Implanon discontinuation becomes unacceptably high in different parts of the country and becomes a programming challenge. Studies from Ethiopia showed 16\% of women discontinued in the first years of Implanon insertion [11], and it reached $46.5 \%$ at the end of three years [12].

Discontinuation while still in need (DWSIN) is particularly problematic, and it leaves women at risk of unwanted pregnancy. Around 15 to 20 percent of LARC users faced with an unwanted pregnancy after three months of discontinuation [9]. The incidence of unintended pregnancy secondary to improper switching of another method after discontinuation was high among low-socioeconomic women in developing countries $[13,14]$. Although there is a high number of women who come to health institutions and requesting the removal of Implanon prematurely and its contribution to increasing unwanted pregnancy is high, there is little scientific information available from Ethiopia, particularly in the study areas. This study is aimed at assessing the level of premature Implanon discontinuation and associated factors among women who requested Implanon removal in Andabet district, North-West Ethiopia. The findings of this study may support the Implanon provision program by showing important intervention areas.

\section{Materials and Methods}

The facility-based cross-sectional study design was conducted among women who requested Implanon removal from February 03 to April 28, 2017, in Andabet district, North-West Ethiopia. The district is located $717 \mathrm{~km}$ from Addis Ababa, the capital city of Ethiopia. According to the 2016 health office report, the total population of the district was 139,462 (70,944 males and 68,518 females). Of that, 33,332 were female reproductive-age groups (15-49 years). The district has 24 Kebeles (small administrative units), 5 health centers, and 24 health posts.

2.1. Eligibility Criteria. All women who requested Implanon removal were included in the study.
2.2. Sample Size Determination. The sample size was determined by using the Epi-Info version 7 software by considering the following statistical assumption. Educational status and its odds ratio were taken from a previous study [11].

Assumption: two-sided significant level: $95 \%$, power (1beta): $90 \%$, ratio of sample size: 2 , percent not read and write with the outcome: $50.8 \%$, percent with secondary education with outcome $34.9 \%$ and odds ratio: 0.51 , and continuity correction result $=485$ which is the largest sample size from the factors. Then, by adding a $12 \%$ nonresponse rate, the final sample size $(n)$ is

$$
n=485 * \frac{1}{1-0.12}=544 .
$$

2.3. Sampling Method and Procedures. The calculated sample size was allocated proportionally for each health facility based on the average number of three-month client flow. According to the health facility report that provides Implanon removal service (Andabet health center (HC), Jaragedo HC, AsideMariam HC, Gono HC, and Generate-Mariam HC), a total of 1276 women removed Implanon three months before the survey. The sampling interval was allocated by dividing women booked to remove Implanon (1276 clients) to the current sample size (544), which was every two clients. A systematic random sampling technique was employed to select the study participants (fig. 1 from supplementary file).

2.4. Operational Definition. Implanon discontinuation: removal of the method before three years of insertion [15].

Not implanon discontinuation: removal of the method at three-year completion of insertion [15].

2.5. Data Collection Procedure and Tools. A structured English version questionnaire was adapted from different works of literature that have a related context to the current study $[10,12,13]$ and translated to the local language (Amharic). To assure validity and reliability, the tool content (items), clarity of language use, and comprehensibility were extensively reviewed by experts. Moreover, the questionnaire was pretested among 5\% of the study participants out of the study area to check tool consistency, sensitivity, and understandability in the local context. The data were collected by face-to-face interview. Five trained data collectors who have a diploma in health sciences (level-IV) and two supervisors who have a BSc degree in nursing participated in data collection.

2.6. Data Management and Analysis. Data were entered in Epi-Info version 7 and then exported to the Statistical package for social sciences (SPSS) version 20.0 software for analysis.

Both descriptive and analytical statistical analysis was done. Bivariate analysis was computed to select the candidate variables for multivariable analysis at $p$ value $\leq 0.2$. Variables with a $p$ value $<0.05$ in the multivariable binary logistic regression analysis were considered predictor variables for Implanon discontinuation. The adjusted odds ratio (AOR) with its corresponding 95\% confidence interval (CI) was used to show the strength of association. Multicollinearity between each explanatory variable was checked by using 
TABLE 1: Sociodemographic characteristics of women who requested the removal of Implanon in Andabet district, public health facilities, North-West Ethiopia, 2017.

\begin{tabular}{|c|c|c|}
\hline Variables $(n=537)$ & Frequency & Percentage \\
\hline \multicolumn{3}{|l|}{$A g e^{*}$} \\
\hline$<20$ & 53 & 9.9 \\
\hline $21-24$ & 66 & 12.3 \\
\hline $25-29$ & 149 & 27.7 \\
\hline $30-34$ & 155 & 28.9 \\
\hline$>35$ & 114 & 21.2 \\
\hline \multicolumn{3}{|l|}{ Marital status } \\
\hline Married & 498 & 92.7 \\
\hline Single & 29 & 5.4 \\
\hline Others (widowed and divorce) & 10 & 1.9 \\
\hline \multicolumn{3}{|l|}{ Educational status } \\
\hline Have no formal education & 406 & 75.6 \\
\hline Primary education & 61 & 11.4 \\
\hline Secondary education & 26 & 4.8 \\
\hline Certificate and above & 44 & 8.2 \\
\hline \multicolumn{3}{|c|}{ Husband/partner education $(n=516)$} \\
\hline Have no formal education & 398 & 77.1 \\
\hline Primary education & 51 & 9.9 \\
\hline Secondary education & 18 & 3.5 \\
\hline Certificate and above & 49 & 9.5 \\
\hline \multicolumn{3}{|l|}{ Religion } \\
\hline Orthodox & 527 & 98.1 \\
\hline Muslim & 10 & 1.9 \\
\hline \multicolumn{3}{|l|}{ Occupation } \\
\hline Housewife & 432 & 80.4 \\
\hline Merchant & 42 & 7.8 \\
\hline Government employee & 37 & 6.9 \\
\hline Farmer & 24 & 4.5 \\
\hline Student & 2 & 0.4 \\
\hline \multicolumn{3}{|l|}{ Have live children } \\
\hline Yes & 444 & 82.7 \\
\hline No & 93 & 17.3 \\
\hline \multicolumn{3}{|l|}{ Need more children $(n=444)$} \\
\hline Yes & 348 & 78.4 \\
\hline No & 96 & 21.6 \\
\hline \multicolumn{3}{|l|}{ History of abortion } \\
\hline Yes & 58 & 10.8 \\
\hline No & 479 & 89.2 \\
\hline \multicolumn{3}{|c|}{$\begin{array}{l}\text { Perceived her spouse wants to give birth } \\
\text { in the next two years }(n=516)\end{array}$} \\
\hline Yes & 261 & 50.6 \\
\hline No & 255 & 49.4 \\
\hline \multicolumn{3}{|l|}{ Purpose of using contraceptive } \\
\hline Spacing & 437 & 81.4 \\
\hline Limiting & 100 & 18.6 \\
\hline
\end{tabular}

TABLE 1: Continued.

\begin{tabular}{lcc}
\hline Variables $(n=537)$ & Frequency & Percentage \\
\hline Feeling of women if pregnant soon & & \\
Being happy & 179 & 33.3 \\
Neutral & 148 & 27.6 \\
Being sad & 210 & 39.1 \\
\hline
\end{tabular}

${ }^{*}$ The age classification was done based on the previous studies [11, 12, 15].

standard errors. The chi-square assumption was also checked with the contingency tables of the expected and observed frequency. Model fitness was checked by using the HosmerLemeshow goodness of fit test $(p>0.05)$ [15].

\section{Results}

3.1. Sociodemographic and Reproductive Characteristics of the Study Participants. A total of 537 women participated in the survey, making a response rate of $98.7 \%$. The age ranges of the participants were between 16 and 47 years with the mean $( \pm S D)$ age of $29.38 \pm 6.30$ years. The majority of the respondents were 498 (92.7\%) married, 527 (98.1\%) Orthodox in religion, and $432(80.4 \%)$ housewives in occupation (Table 1).

3.2. Family Planning Service-Related Characteristics of the Study Participants. Before Implanon use, 97.2\% of women had information for at least one type of contraceptive method; 519 (96.6\%) women had information about injectable, $446(83.1 \%)$ about pills, $117(21.8 \%)$ about condom, 79 (14.7\%) about IUCD, and 23 (4.3\%) women had information about permanent family planning methods. Most women got information from health professionals. Four hundred forty-four (82.7\%) women had ever used other contraceptive methods before using Implanon. 90\% of them used injectable contraceptives.

Four hundred seventeen women $(77.6 \%)$ reported that the long-term duration of protection from unwanted pregnancy was their reason for choosing to use Implanon. Hence, $94(17.5 \%)$ women reported that the unavailability of other method choice was their reason for choosing to use Implanon (Table 2).

3.3. Level and Time for Implanon Discontinuation. According to this study, out of the total 537 women who requested Implanon removal, 198 (36.9\%) ( $p=36.9 \%$, 95\% CI: 33.0\%$41.2 \%)$ women discontinued the method before its intended period. The most reported reasons for discontinuation were the presence of side effects 136 (68.7\%) followed by want to be pregnant 55 (27.7\%) (fig. 2 from supplementary-file). The discontinuation of Implanon starts as early as 01 month and as long as 35 months with a mean $( \pm$ SD) of $15.56 \pm 7.82$ months of use (Figure 1).

3.4. Factors Associated with Implanon Discontinuation. In multivariable binary logistic regression analysis, there were a higher odds of Implanon discontinuation among women who had no live child (AOR $=2.17,95 \% \mathrm{CI}: 1.25-3.77)$, had 
TABLE 2: Family planning service-related characteristics of women who requested the removal of Implanon in Andabet district, public health facilities, North-West Ethiopia, 2017.

\begin{tabular}{|c|c|c|}
\hline Variables $(n=537)$ & Frequency & Percentage \\
\hline \multicolumn{3}{|l|}{ Ever heard about contraceptive } \\
\hline Yes & 522 & 97.2 \\
\hline No & 15 & 2.8 \\
\hline \multicolumn{3}{|l|}{$\begin{array}{l}\text { Ever used any contraceptive before } \\
\text { Implanon use }\end{array}$} \\
\hline Yes & 444 & 82.7 \\
\hline No & 93 & 17.3 \\
\hline \multicolumn{3}{|l|}{ Preinsertion counseling } \\
\hline Yes & 393 & 73.2 \\
\hline No & 144 & 26.8 \\
\hline \multicolumn{3}{|l|}{ Counseling type $(n=393)$} \\
\hline Individual & 327 & 83.2 \\
\hline Mass counseling & 42 & 10.7 \\
\hline Couple & 24 & 6.1 \\
\hline \multicolumn{3}{|l|}{$\begin{array}{l}\text { Topics discussed during } \\
\text { counseling }(n=393)\end{array}$} \\
\hline Benefit (advantage) & 327 & $83 . .2$ \\
\hline Side effect & 193 & 49.1 \\
\hline Duration of action & 312 & 79.4 \\
\hline Effectiveness & 107 & 27.2 \\
\hline Time of insertion and removal & 270 & 68.3 \\
\hline \multicolumn{3}{|l|}{$\begin{array}{l}\text { Discuss with husband/partner } \\
\text { to use Implanon }\end{array}$} \\
\hline Yes & 349 & 65.0 \\
\hline No & 188 & 35.0 \\
\hline \multicolumn{3}{|l|}{$\begin{array}{l}\text { Women accompanied by at the time } \\
\text { of service provision }\end{array}$} \\
\hline No one accompanied & 417 & 77.7 \\
\hline Husband/partner & 91 & 16.9 \\
\hline Mother & 16 & 3.0 \\
\hline Others & 13 & 2.4 \\
\hline \multicolumn{3}{|l|}{ Who insist you use Implanon? } \\
\hline Women herself & 317 & 59.0 \\
\hline Couple together & 79 & 14.7 \\
\hline Health provider & 74 & 13.8 \\
\hline Husband/partner & 67 & 12.5 \\
\hline \multicolumn{3}{|l|}{ Place of Implanon insertion } \\
\hline Health post & 290 & 54.0 \\
\hline Health center & 247 & 46.0 \\
\hline \multicolumn{3}{|l|}{ Reason for using Implanon } \\
\hline The long duration of action & 417 & 77.6 \\
\hline Need low follow-up time & 307 & 57.2 \\
\hline Unavailability of other methods & 94 & 17.2 \\
\hline Less side effect & 60 & 11.2 \\
\hline Effectiveness & 25 & 4.7 \\
\hline
\end{tabular}

TABle 2: Continued.

\begin{tabular}{lcc}
\hline Variables $(n=537)$ & Frequency & Percentage \\
\hline $\begin{array}{l}\text { Have appointment follow-up after } \\
\text { Implanon insertion }\end{array}$ & & \\
$\quad$ Yes & 151 & 28.1 \\
$\quad$ No & 386 & 71.9 \\
Perceived satisfaction by the service & & \\
provided & & \\
$\quad$ Yes & 435 & 81.0 \\
$\quad$ No & 102 & 19.0 \\
\hline
\end{tabular}

no history of abortion ( $\mathrm{AOR}=2.62,95 \% \mathrm{CI}$ : 1.18-5.44), women felt happy if pregnant soon compared to who felt sad $(\mathrm{AOR}=2.66,95 \% \mathrm{CI}: 1.59-4.45)$, did not receive preinsertion counseling on potential side effects $(\mathrm{AOR}=1.85$, 95\% CI: 1.15-2.97), developed Implanon-related side effect $(\mathrm{AOR}=5.17,95 \% \mathrm{CI}: 3.18-8.40)$, and women who were not satisfied by the service given $(\mathrm{AOR}=5.40,95 \% \mathrm{CI}$ : 3.04 9.57) compared to their counterparts. On the other hand, women who received follow-up services have lower odds of Implanon discontinuation $(\mathrm{AOR}=0.23,95 \% \mathrm{CI}: 0.13-0.41)$ (Table 3).

\section{Discussions}

This study examined the prevalence of Implanon discontinuation ad and associated factors among women who requested Implanon removal in Andabet district, North-West Ethiopia.

The overall discontinuation of Implanon was 36.9\% (95\% CI: $33.0 \%-41.2 \%)$ with $15.56 \pm 7.82$ months' mean duration of use. This finding is consistent with the study conducted in Kucha district, Southern Ethiopia (34\%) [16], Ghana (40\%) [17], and India (37\%) [18]. However, this finding is higher than the study done in Zaria (19\%) [19], Ilorin in Nigeria (26.1\%) [20], and the US population (25.2\%) [21]. The first plausible reason for this difference might be due to a difference in preinsertion counseling and follow-up services. During counseling, women can get detailed information about Implanon to correct misconceptions [22, 23]. The second reason might be different in women's experience for Implanon use. All participants in Zaria, Nigeria, had a history of Implanon use [22]. However, in the current study, all participants were new to this method. Women's previous experience with Implanon can help them to tolerate minor side effects for the second use [24]. On the other hand, this finding is lower than the study done in Debretabor Town (65\%) [25], Hawassa, Southern Ethiopia (49.3\%) [26], and Uganda (56\%) [27]. The possible reason for the lower discontinuation rate in this study might be sociodemographic differences of respondents across the study areas. The number of living children might contribute to this lower Implanon discontinuation; in the current study, $82.7 \%$ of respondents have living children whereas $65 \%$ from the study done at Debretabor Town [25]. This might insist the women discontinue the method before the intended time for giving birth. A desire for pregnancy is one of the main reasons for contraceptive discontinuation $[12,25,28]$. The other possible 


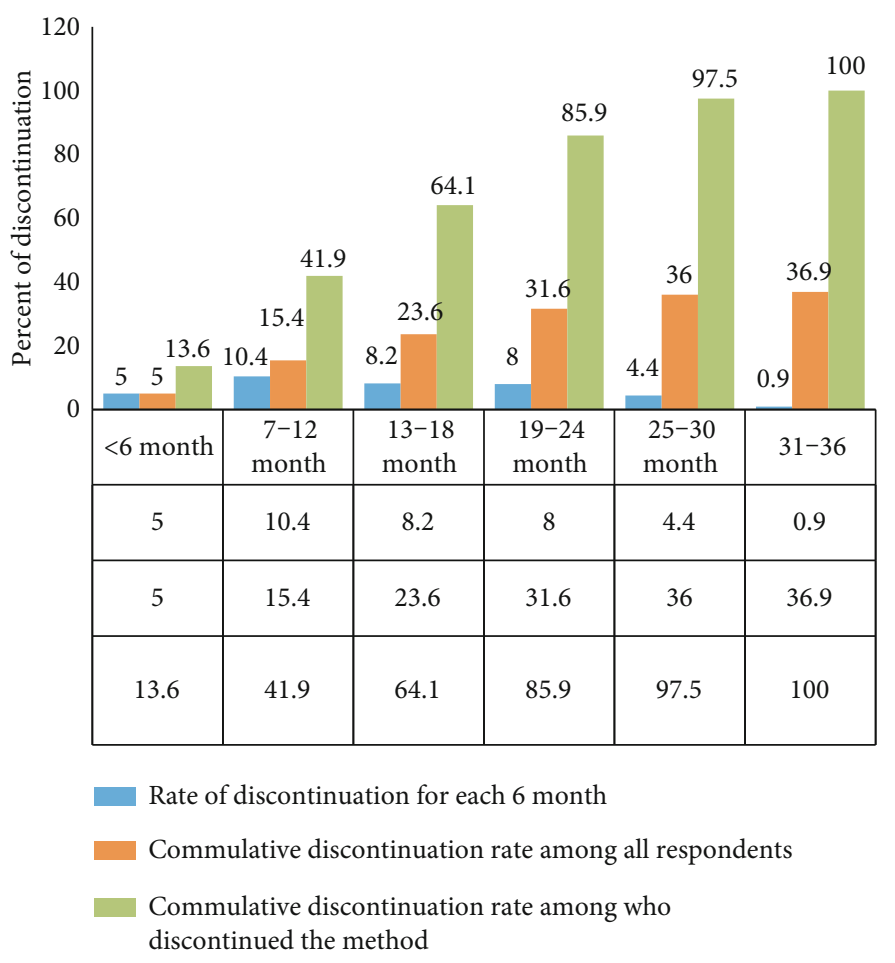

FiguRE 1: Rate of Implanon discontinuation among women who requested the removal of Implanon in Andabet district, public health facilities; North-West Ethiopia, 2017.

reason might also be the difference in the accessibility of other alternative contraceptives. In Ethiopia, most urban women have better contraceptive access compared to the rural women [29]. Since the current study participant is rural women, they might have limited access to other alternative contraceptives, and this might insist them to tolerate minor side effects of Implanon as compared to the aforementioned urban-based studies [25, 26].

According to the findings of this study, the predominant reason for Implanon discontinuation reported by the women was Implanon-related side effects followed by the desire for pregnancy. This is similar to other studies in Ethiopia [12, 28]. However, this finding was different from the studies from Jos, Central Nigeria [30]. The possible reason might be different in women's menstrual condition. About $85.5 \%$ of women have regular menstruation in Jos, Central Nigeria [30], and only $20.5 \%$ of respondents have had regular menstruation in the current study. For many women, menstrual bleeding is the main reason for contraceptive discontinuation $[24,31,32]$.

In this study, women who had a history of abortion had low odds of Implanon discontinuation compared to their counterparts. This finding is supported by the study conducted in seven different countries [33]. The possible explanation for this might be due to information and understanding differences about unintended pregnancy, abortion, and related complications. Women who have a history of abortion might learn from their previous bad experiences.

Implanon discontinuation has higher odds among women who had no live children compared to their counter- parts. This is similar to the study done in Debre Markos town [12]. In most cases, women who have no live children have more fertility desires compared to those who have live children. Those women might also be influenced by their families to give birth before they become infertile [34-36].

Other findings of this study showed women who reported that they felt happy if they become pregnant soon have high odds of Implanon discontinuation compared to those who felt sad. This is supported by a study done in Ofla district and Jos, Central Nigeria [13,30]. The desire for childbirth is a common reason for contraceptive discontinuation. This also reflects women's commitment to preventing unintended pregnancy. Those women who committed to preventing unintended pregnancy might tolerate minor side effects of the method $[37,38]$.

Women who did not receive preinsertion counseling about the potential side effects of the method had high odds of Implanon discontinuation compared to those who received counseling. This finding is supported by the study done in Debre Markos town [12]. The possible reason might be women who are counseled about side effects can develop preset mind about it and be able to tolerate possible minor side effects. Moreover, the information provided during counseling can clear the women's misconceptions that might cause discontinuation [39].

In this study, there are high odds of Implanon discontinuation among women who had not satisfied with the service provided compared to those who were satisfied. This is consistent with studies done in Ethiopia $[11,12,16]$. This might be true that service satisfaction at first contact 
TABLE 3: Factors associated with discontinuation of Implanon among women who requested the removal of Implanon in Andabet district, public health facilities, North-West Ethiopia, 2017.

\begin{tabular}{|c|c|c|c|c|}
\hline \multirow[t]{2}{*}{ Variables $(n=537)$} & \multicolumn{2}{|c|}{$\begin{array}{c}\text { Implanon } \\
\text { discontinuation }\end{array}$} & \multirow[t]{2}{*}{ COR (95\% CI) } & \multirow[t]{2}{*}{ AOR (95\% CI) } \\
\hline & Yes & No & & \\
\hline \multicolumn{5}{|l|}{ Educational status } \\
\hline No formal education & 141 & 265 & 1 & 1 \\
\hline Primary & 20 & 41 & $0.92(0.52-1.63)$ & $1.27(0.58-2.81)$ \\
\hline Secondary & 14 & 12 & $2.19(0.99-4.87)$ & $2.50(0.91-6.88)$ \\
\hline Certificate and above & 23 & 21 & $2.06(1.10-3.85)$ & $1.71(0.70-4.16)$ \\
\hline \multicolumn{5}{|l|}{ Living children } \\
\hline Yes & 153 & 288 & 1 & 1 \\
\hline No & 45 & 51 & $1.66(1.06-2.60)$ & $2.17(1.25-3.77)^{*}$ \\
\hline \multicolumn{5}{|l|}{ History of abortion } \\
\hline Yes & 14 & 44 & 1 & 1 \\
\hline No & 184 & 295 & $1.96(1.05-3.68)$ & $2.62(1.18-5.44)^{*}$ \\
\hline \multicolumn{5}{|c|}{ Feeling of women if pregnant soon } \\
\hline Happy & 88 & 91 & $2.48(1.63-3.78)$ & $2.66(1.59-4.45)^{* *}$ \\
\hline Neutral & 51 & 97 & $1.35(0.86-2.12)$ & $1.09(0.63-1.91)$ \\
\hline Will be sad & 59 & 151 & 1 & 1 \\
\hline \multicolumn{5}{|c|}{ Purpose of using the method } \\
\hline For spacing & 172 & 265 & $1.85(1.14-3.00)$ & $1.21(0.59-2.49)$ \\
\hline For limiting & 26 & 74 & 1 & 1 \\
\hline \multicolumn{5}{|c|}{ Main decider to use Implanon } \\
\hline Women her self & 108 & 209 & 1 & 1 \\
\hline Husband/partner & 27 & 40 & $1.31(0.76-1.31)$ & $0.88(0.45-1.75)$ \\
\hline Couple together & 20 & 59 & $0.66(0.38-1.15)$ & $0.90(0.45-1.80)$ \\
\hline Service provider & 43 & 31 & $2.68(1.60-4.50)$ & $1.71(0.90-3.24)$ \\
\hline \multicolumn{5}{|l|}{ Counseled about benefit } \\
\hline Yes & 109 & 206 & 1 & \\
\hline No & 89 & 123 & $1.43(1.00-2.05)$ & $0.96(0.59-1.57)$ \\
\hline \multicolumn{5}{|c|}{ Counseled about side effect } \\
\hline Yes & 56 & 135 & 1 & 1 \\
\hline No & 142 & 204 & $1.68(1.15-2.45)$ & $1.85(1.15-2.97)^{*}$ \\
\hline \multicolumn{5}{|c|}{ Discussed with their partner } \\
\hline Yes & 120 & 229 & 1 & \\
\hline No & 78 & 110 & $1.35(0.94-1.94)$ & $1.16(0.70-1.92)$ \\
\hline \multicolumn{5}{|l|}{ Presence of side effect } \\
\hline Yes & 162 & 150 & $5.67(3.73-8.63)$ & $5.17(3.18-8.40)^{* *}$ \\
\hline No & 36 & 189 & 1 & 1 \\
\hline \multicolumn{5}{|c|}{ Had appointment follow-up } \\
\hline Yes & 20 & 131 & $0.18(0.11-0.0 .30)$ & $0.23(0.13-0.41)^{* *}$ \\
\hline No & 178 & 208 & 1 & 1 \\
\hline \multicolumn{5}{|c|}{ Satisfied by the service provided } \\
\hline Yes & 119 & 316 & 1 & 1 \\
\hline No & 79 & 23 & $9.12(5.48-15.19)$ & $5.40(3.04-9.57)^{* *}$ \\
\hline
\end{tabular}

Note: * statistically significant at $p<0.05$ and ${ }^{* *}$ statistically significant at $p<0.001$.

can increase the continuation of a longitudinal type of service use $[40,41]$. Service satisfaction can increase the affection between women and service providers. This enables women to perform what the providers said before discontinuing the method and can tolerate minor side effects of the methods, because those women can develop confidence due 
to caring professionals that treating possible side effects early [42].

Appointment follow-up had a statistical association with Implanon discontinuation. Women who had an appointment follow-up service have a lower odds of discontinuing the method compared to their counterparts. This is similar to other studies $[11,43]$. During follow-up, women may get further detailed counseling and information regarding women's concerns or misconceptions about the method. Furthermore, those women can get management for the developed side effects and may continue with management.

In the current study, the primary reason for discontinuation was facing Implanon-related side effects. The odds of Implanon discontinuation among women who developed side-effect were higher compared to their counterparts. This finding is consistent with the study conducted in Debre Markos and Ofla district $[11,12]$. This might be women's intolerance to the newly occurring minor side effects of the method. The other reason might be women who develop vaginal bleeding may interfere with their sexual experience and feel guilt by the usual occurrence of bleeding.

The current study has some limitations; since most variables are assessed retrospectively, there may be recall bias (the women may not remember some information conducted during Implanon insertion). The other limitations are the survey was assessed by using the quantitative data and the lack of women's exploration of the methods and type of services they used.

\section{Conclusions}

The level of Implanon discontinuation in this study was high. Further study is recommended to investigate its contribution to the total unwanted population fertility. The main reasons for discontinuation were method-related side effects followed by a desire for childbirth. Having children at the time of insertion, history of abortion, feeling of women if got pregnant, preinsertion counseling, developed side effects, received appointment follow-up, and perceived service satisfaction were the predictors for Implanon discontinuation. Strengthening contraceptive counseling and appointment follow-up services might increase Implanon continuation. Working to improve clients' perceived satisfaction could also reduce Implanon discontinuation.

\section{Abbreviations \\ EDHS: Ethiopian Demographic and Health Survey \\ FMOH: Federal Ministry of Health of Ethiopia \\ HC: $\quad$ Health center \\ $\mathrm{km}$ : Kilometer \\ LARCs: Long-acting reversible contraceptives \\ DWSIN: Discontinuation while still in need.}

\section{Data Availability}

The data that supported the findings are readily available in supplementary material.

\section{Ethical Approval}

Ethical clearance was obtained from Bahir Dar University Ethical Review committee with ethical reference number (囚/囚/囚/囚/1/552/109). Permission letters were received from Amhara National Regional Health Bureau and Andabet District Health Office.

\section{Consent}

Informed written consent was taken from all study participants after providing a clear explanation about the study. And participation was entirely voluntary. For participants age below 18 years and not mature minors, the written consent was taken from their legal guardians. Information obtained from the study participants was kept confidential.

\section{Conflicts of Interest}

We do not have any competing interests.

\section{Authors' Contributions}

GWD conceived and designed the study. GWD, YMG, MBA, and ZAA were equally involved in the analysis, interpretation, and writing of the results. All authors read and approve the final manuscript.

\section{Acknowledgments}

We would like to thank Bahir Dar University for providing us ethical clearance to conduct the study. Furthermore, we would like to appreciate Andabet district health professionals for their invaluable support and cooperation. Our great thank extends to all women data collectors and supervisors who participated in this study. We also acknowledge the Research Square Team for submitting this manuscript online as a preprint. This is the link: https://www.researchsquare .com/article/rs-3226/v1.

\section{Supplementary Materials}

Description of supplementary file: the supplementary file comprises of two figures; the first figure is detail about the sampling procedure, and the second is about "Kaplan Meier survival" distribution of the main reasons for Implanon discontinuation. (Supplementary Materials)

\section{References}

[1] O. Meirik, I. S. Fraser, C. d'Arcangues, and WHO Consultation on Implantable Contraceptives for Women, "Implantable contraceptives for women," Human Reproduction Update, vol. 9, no. 1, pp. 49-59, 2003.

[2] R. Jacobstein and H. Stanley, "Contraceptive implants: providing better choice to meet growing family planning demand," Global Health: Science and Practice, vol. 1, no. 1, pp. 11-17, 2013.

[3] L. Bahamondes and M. V. Bahamondes, "New and emerging contraceptives: a state-of-the-art review," International Journal of Women's Health, vol. 6, p. 221, 2014. 
[4] D. Ramchandran and U. D. Upadhyay, "Implants: the next generation," Population reports. Series K: Injectables and implants, vol. 7, pp. 1-19, 2007.

[5] P. Darney, A. Patel, K. Rosen, L. S. Shapiro, and A. M. Kaunitz, "Safety and efficacy of a single-rod etonogestrel implant (Implanon): results from 11 international clinical trials," Fertility and Sterility, vol. 91, no. 5, pp. 1646-1653, 2009.

[6] D. Hubacher, A. Olawo, C. Manduku, J. Kiarie, and P. L. Chen, "Preventing unintended pregnancy among young women in Kenya: a prospective cohort study to offer contraceptive implants," Contraception, vol. 86, no. 5, pp. 511-517, 2012.

[7] L. Alkema, V. Kantorova, C. Menozzi, and A. Biddlecom, "National, regional, and global rates and trends in contraceptive prevalence and unmet need for family planning between 1990 and 2015: a systematic and comprehensive analysis," The Lancet, vol. 381, no. 9878, pp. 1642-1652, 2013.

[8] World Health Organization, Annual technical report: 2013: department of reproductive health and research, including UNDP/UNFPA/WHO/World Bank Special Programme of Research Training in Human Reproduction (HRP), World Health Organization, 2014.

[9] S. Staveteig, L. Mallick, and R. Winter, "Uptake and Discontinuation of Long-Acting Reversible Contraceptives (LARCS) in Low-Income Countries," DHS analytical studies, vol. 54, 2015.

[10] M. Asnake, E. G. Henry, Y. Tilahun, and E. Oliveras, "Addressing unmet need for long-acting family planning in Ethiopia: uptake of single-rod progestogen contraceptive implants (Implanon) and characteristics of users," International Journal of Gynecology \& Obstetrics, vol. 123, pp. e29-e32, 2013.

[11] K. Birhane, S. Hagos, and M. Fantahun, "Early discontinuation of implanon and its associated factors among women who ever used Implanon in Ofla District, Tigray, Northern Ethiopia," International Journal of Pharma Sciences and Research, vol. 6, no. 3, pp. 544-551, 2015.

[12] M. Siyoum, "Implanon discontinuation rate and associated factors among women who ever used Implanon in the last three years in Debre Markos town, Northwest Ethiopia, 2016, cross sectional study," ARC Journal of Public Health and Community of Medicine, vol. 2, no. 1, pp. 8-16, 2017.

[13] S. E. Bradley, C. B. Polis, A. Bankole, and T. Croft, "Global contraceptive failure rates: who is most at risk?," Studies in Family Planning, vol. 50, no. 1, pp. 3-24, 2019.

[14] M. Puri, J. T. Henderson, C. C. Harper, M. Blum, D. Joshi, and C. H. Rocca, "Contraceptive discontinuation and pregnancy postabortion in Nepal: a longitudinal cohort study," Contraception, vol. 91, no. 4, pp. 301-307, 2015.

[15] D. W. Hosmer Jr., S. Lemeshow, and R. X. Sturdivant, Applied logistic regression. Vol. 398, John Wiley \& Sons, 2013.

[16] Mamecha Mesha, Akalewold Alemayehu, and Deresse Daka, "Prevalence and factors associated with early discontinuation rate of Implanon utilization among women who ever used Implanon in Kucha District Gamo Gofa Zone, Southern Ethiopia," BMC Women's Health, vol. 20, no. 1, p. 239, 2020.

[17] E. J. Modey, R. Aryeetey, and R. Adanu, "Contraceptive discontinuation and switching among Ghanaian women: evidence from the Ghana Demographic and Health Survey, 2008," African Journal of Reproductive Health, vol. 18, no. 1, pp. 84-92, 2014.

[18] P. Bhatia, S. Nangia, S. Aggarwal, and C. Tewari, "Implanon: subdermal single rod contraceptive implant," The Journal of
Obstetrics and Gynecology of India, vol. 61, no. 4, pp. 422425, 2011.

[19] N. Madugu, M. A. Abdul, U. Bawa, and B. Kolawole, "Uptake of hormonal implants contraceptive in Zaria, Northern Nigeria," Open Journal of Obstetrics and Gynecology, vol. 5, no. 5, pp. 268-273, 2015.

[20] O. Balogun, N. Olaomo, A. S. Adeniran, and A. A. Fawole, "Implanon sub-dermal implant: an emerging method of contraception in Ilorin, Nigeria," Journal of Medical and Biomedical Sciences, vol. 3, no. 1, pp. 1-5, 2014.

[21] P. M. Casey, M. E. Long, M. L. Marnach, and J. E. Bury, "Bleeding related to etonogestrel subdermal implant in a US population," Contraception, vol. 83, no. 5, pp. 426-430, 2011.

[22] A. Adeyemi and D. Adekanle, "Progestogen-only injectable contraceptive: experience of women in Osogbo, southwestern Nigeria," Annals of African Medicine, vol. 11, no. 1, pp. 2731, 2012.

[23] T. Bekele, A. Gebremariam, and P. Tura, "Factors associated with contraceptive discontinuation in Agarfa district, Bale zone, Southeast Ethiopia," Epidemiology, vol. 5, no. 179, 2015.

[24] A. M. Teunissen, B. Grimm, and F. J. Roumen, "Continuation rates of the subdermal contraceptive Implanon ${ }^{\circledR}$ and associated influencing factors," The European Journal of Contraception \& Reproductive Health Care, vol. 19, no. 1, pp. 15-21, 2014.

[25] M. Melkamu Asaye, T. Syoum Nigussie, and W. Mequannt Ambaw, "Early Implanon discontinuation and associated factors among Implanon user women in Debre Tabor town, public health facilities, Northwest Ethiopia, 2016," International Journal of reproductive medicine, vol. 2018, Article ID 3597487, 10 pages, 2018.

[26] B. A. Abebe and M. R. Terefe, "Discontinuation of implant use and associated factors among women attending health facility clinics in Hawassa City, Southern Ethiopia, 2019; a cross sectional study," Contraception and Reproductive Medicine, vol. 5, no. 1, pp. 1-11, 2020.

[27] S. Staveteig, L. Mallick, R. Winter, and S. Assaf, "Discontinuation of long-acting reversible contraceptives (LARCs) in lowincome countries: the role of method access and programmatic quality," in Proceedings of the 2016 Annual Meeting, PAA, Vancouver, Canada, 2016.

[28] A. Burusie, "Reasons for premature removal of Implanon among users in Arsi zone, Oromia region, Ethiopia, 2013," Reproductive System \& Sexual Disorders, vol. 4, no. 1, 2015.

[29] A. Alvergne, M. A. Gibson, E. Gurmu, and R. Mace, "Social transmission and the spread of modern contraception in rural Ethiopia," PLoS One, vol. 6, no. 7, article e22515, 2011.

[30] V. C. Pam, J. T. Mutihir, J. A. Karshima, M. L. Kahansim, J. Musa, and P. H. Daru, "Factors associated with use and discontinuation of Implanon contraceptive in Jos, Nigeria," Tropical Journal of Obstetrics and Gynaecology, vol. 31, no. 2, pp. 90-99, 2014.

[31] E. Tolley, S. Loza, L. Kafafi, and S. Cummings, "The impact of menstrual side effects on contraceptive discontinuation: findings from a longitudinal study in Cairo, Egypt," International Family Planning Perspectives, vol. 31, no. 1, pp. 1523, 2005.

[32] C. O. Njoku, C. I. Emechebe, C. U. Iklaki, A. N. Njoku, and J. T. Ukaga, "Progestogen-only injectable contraceptives: the profile of the acceptors, side effects and discontinuation in a 
low resource setting, Nigeria," Open Journal of Obstetrics and Gynecology, vol. 6, no. 4, pp. 189-195, 2016.

[33] C. Marston and J. Cleland, "Relationships between contraception and abortion: a review of the evidence," International Family Planning Perspectives, vol. 29, no. 1, pp. 6-13, 2003.

[34] T. Tilahun, G. Coene, M. Temmerman, and O. Degomme, "Spousal discordance on fertility preference and its effect on contraceptive practice among married couples in Jimma zone, Ethiopia," Reproductive Health, vol. 11, no. 1, 2014.

[35] M. Kassa, A. A. Abajobir, and M. Gedefaw, "Level of male involvement and associated factors in family planning services utilization among married men in Debremarkos town, Northwest Ethiopia," BMC International Health and Human Rights, vol. 14, no. 1, p. 33, 2014.

[36] H. Gebremichael, "Acceptance of long- acting contraceptive methods and associated factors among women in Mekelle city, Northern Ethiopia," Science Journal of Public Health, vol. 2, no. 4, pp. 349-355, 2014.

[37] S. Curtis, E. Evens, and W. Sambisa, "Contraceptive discontinuation and unintended pregnancy: an imperfect relationship," International Perspectives on Sexual and Reproductive Health, vol. 37, no. 2, pp. 058-066, 2011.

[38] J. L. Barden-O'Fallon, I. S. Speizer, and J. S. White, “Association between contraceptive discontinuation and pregnancy intentions in Guatemala," Revista Panamericana de Salud Pública, vol. 23, no. 6, pp. 410-417, 2008.

[39] C. Dehlendorf, K. Levy, A. Kelley, K. Grumbach, and J. Steinauer, "Women's preferences for contraceptive counseling and decision making," Contraception, vol. 88, no. 2, pp. 250-256, 2013.

[40] J. R. Rosenstock, J. F. Peipert, T. Madden, Q. Zhao, and G. M. Secura, "Continuation of reversible contraception in teenagers and young women," Obstetrics and Gynecology, vol. 120, no. 6, pp. 1298-1305, 2012.

[41] K. I. Black, D. Bateson, and C. Harvey, "Australian women need to increased access to long-acting reversible contraception," The Medical Journal of Australia, vol. 199, no. 5, pp. 317-318, 2013.

[42] J. F. Peipert, Q. Zhao, J. E. Allsworth et al., "Continuation and satisfaction of reversible contraception," Obstetrics and Gynecology, vol. 117, no. 5, pp. 1105-1113, 2011.

[43] A. Tadesse, M. Kondale, E. Agedew, F. Gebremeskel, N. Boti, and B. Oumer, "Determinant of Implanon discontinuation among women who ever used Implanon in Diguna Fango District, Wolayita zone, southern Ethiopia: a community-based case control-study," International Journal of reproductive medicine, vol. 2017, 8 pages, 2017. 